\title{
Is there a relationship between complaints of impaired balance and postural control disorder in community-dwelling elderly women? A cross-sectional study with the use of posturography
}

\author{
Erika H. Tanaka ${ }^{1}$, Paulo F. Santos ${ }^{1}$, Júlia G. Reis ${ }^{1}$, Natalia C. Rodrigues ${ }^{1}$, \\ Renato Moraes ${ }^{2}$, Daniela C. C. Abreu ${ }^{1}$
}

\begin{abstract}
Background: Risk of falls increases as age advances. Complaints of impaired balance are very common in the elderly age group. Objectives: The objective of this study was to investigate whether the subjective perception of impaired balance was associated with deficits in postural control (objective analysis) in elderly community-dwelling women. Method: Static posturography was used in two groups: elderly women with (WC group) and without (NC group) complaints of impaired balance. The area, mean sway amplitude and mean speed of the center of pressure (COP) in the anterior-posterior (AP) and medial-lateral (ML) directions were analyzed in three stances: single-leg stance, double-leg stance and tandem stance, with eyes open or closed on two different surfaces: stable (firm) and unstable (foam). A digital chronometer was activated to measure the time limit (Tlimit) in the single-leg stance. Kruskal-Wallis tests followed by Mann-Whitney tests, Friedman analyses followed by post hoc Wilcoxon tests and Bonferroni corrections, and Spearman statistical tests were used in the data analysis. Differences of $\mathrm{p}<0.05$ were considered statistically significant. Results: The results of posturography variables revealed no differences between groups. The timed single-leg stance test revealed a shorter Tlimit in the left single-leg stance $(\mathrm{p}=0.01)$ in WC group compared to NC group. A negative correlation between posturography variables and Tlimit was detected. Conclusions: Posturography did not show any differences between the groups; however, the timed single-leg stance allowed the authors to observe differences in postural control performance between elderly women with and those without complaints of impaired balance.
\end{abstract}

Keywords: falls; postural balance; elderly; posture; physical therapy specialty.

Registration number of clinical trials: Rebec RBR-3s9m65.

\section{HOW TO CITE THIS ARTICLE}

Tanaka EH, Santos PF, Reis JG, Rodrigues NC, Moraes R, Abreu DCC. Is there a relationship between complaints of impaired balance and postural control disorder in community-dwelling elderly women? A cross-sectional study with the use of posturography. Braz J Phys Ther. 2015 May-June; 19(3):186-193. http://dx.doi.org/10.1590/bjpt-rbf.2014.0086

\section{Introduction}

The risk of falls increases with age ${ }^{1}$ and it has been predicted that one-third of the community-dwelling elderly will fall over the course of one year ${ }^{2}$. After the first fall, elderly individuals become vulnerable to subsequent falls ${ }^{3}$. Thus, preventing the first fall seems to be essential if one is hoping to minimize the possibility of subsequent falls.

In addition, the prevention of falls is a potential means of preventing post-fall consequences, such as hospitalization, loss or reduction of independence, psychological complications (such as fear of falling, post-fall syndrome $)^{4,5}$. Both elderly fallers and non-fallers experience the fear of falling and have complaints of imbalance, which may cause the elderly to restrict their daily life activities (DLA)

Thus, it is important to understand whether self-reported complaints of imbalance are associated with real deficits in postural control. If so, it would enable the referral of these elderly individuals with existing complaints to prevention programs prior to performing tests such as posturography, which is not available in all physical therapy services. Some

${ }^{1}$ Curso de Fisioterapia, Departamento de Biomecânica, Medicina e Reabilitação do Aparelho Locomotor, Faculdade de Medicina de Ribeirão Preto, Universidade de São Paulo (USP), Ribeirão Preto, SP, Brazil

${ }^{2}$ Núcleo de Apoio à Pesquisa em Doenças Crônico-Degenerativas, Escola de Educação Física e Esporte de Ribeirão Preto, Universidade de São Paulo (USP), Ribeirão Preto, SP, Brazil

Received: May 11, 2014 Revised: Aug. 07, 2014 Accepted: Nov. 18, 2014 
studies have used the self-report of imbalance as an evaluation tool ${ }^{7,8}$, although these studies evaluated individuals with dizziness-associated symptoms. Lion et al. ${ }^{8}$ reported a strong correlation between self-reported imbalance and clinical tests such as the Timed Up and Go (TUG), single-leg stance and a 10-m walk. Baloh et al. ${ }^{7}$ demonstrated that patients who self-reported imbalance and dizziness had increased body sway velocity.

However, there is a need to assess whether there is an association between self-reported imbalance and postural control in independent community-dwelling elderly, using different support bases and visual conditions, and with increased task demand to increase the sensitivity of the assessment ${ }^{9,10}$. The aim was to identify subtle deficits in postural contro ${ }^{10}$ because the performance of postural control is the result of the complex integration and coordination of multiple systems ${ }^{11}$ dependent on the central processing of inputs of the afferent visual, vestibular and somatosensory systems and of the neuromuscular action of efferent mechanisms ${ }^{12}$. The perception of imbalance may be associated with an initial decline of some component(s) of the postural control system.

Therefore, the objective of this study was to investigate whether the subjective perception of imbalance was consistent with postural control deficits in communitydwelling elderly women. The study hypothesis was that elderly women who report complaints of imbalance had greater body sway visualized using a force platform (objective analysis) and shorter stays in single-leg stance (clinical trial) than elderly women who do not report complaints of imbalance, assuming imbalance indicates poor posture control.

\section{- Method}

Forty-four elderly women over the age of 60 years were recruited from the local community from 2011 to 2013 to voluntarily participate in this study. This cross-sectional study was approved by the Human Research Ethics Committee of the Faculdade de Medicina de Ribeirão Preto, Universidade de São Paulo (FMRP-USP), Ribeirão Preto, São Paulo, Brazil, protocol number 5372/2010. All volunteers signed an informed consent before participating in the study.

The elderly women were divided into two groups: 17 with (WC) and 27 with no (NC) complaints of imbalance. Participants were excluded if they had cardiovascular, neurological or musculoskeletal diseases that could interfere with their semi-static or dynamic balance or if they presented with vestibular disorders, peripheral neuropathies or cognitive deficits as indicated by scores less than 24 points on the Mini-Mental State Examination ${ }^{13}$.

The evaluations were performed at the Evaluation and Rehabilitation of Balance Laboratory (Laboratório de Avaliação e Reabilitação do Equilíbrio - LARE), Department of Biomechanics, Medicine and Rehabilitation of the Locomotor System, FMRP-USP. First, the body weight and height were measured for each elderly individual. For the measurement of semi-static balance, a force platform was used during quiet standing posture. For the subjective evaluation of complaints of imbalance, a qualitative questionnaire was used with the following question: "Do you have any imbalance complaints?" The participants had the option to answer "Yes" or "No".

Balance in semi-static stance was measured using the force platform (EMG System do Brasil ${ }^{\circledR}$ ) with an acquisition frequency of $100 \mathrm{~Hz}$ and center of pressure (COP) data filtered with a low-pass $4^{\text {th }}$-order Butterworth digital filter with a cutoff frequency of $10 \mathrm{~Hz}$.

Data on 8 stances were collected for each subject: standing on a fixed platform with eyes open (FPEO) and closed (FPEC); standing on an unstable platform (5-cm-thick foam with a density of $\left.30 \mathrm{~g} / \mathrm{dm}^{3}\right)$ with eyes open (UPEO) and closed (UPEC) ${ }^{14}$; in tandem stance with the right foot in front of the left foot and eyes open (TANDEM EO) and closed (TANDEM EC); and in single-leg stance with eyes open on the right leg (SINGLE R), and standing on the left leg (SINGLE L). The order of evaluation of each stance was randomized, and two attempts were made for each stance, for a total of 16 data collection points for each participant. The bipedal stances were maintained for 60 seconds, the tandem while the single-leg stances were maintained for 30 seconds each. The rest time was approximately 30 seconds between each of the 16 tests.

The number and time of each test were chosen to avoid fatigue in the elderly while maintaining data reliability ${ }^{15}$. The maximum time in single-leg stance, prior to the elderly abandoning the stance or losing their balance by touching the platform with the contralateral foot or touching the therapist with their hands (the therapist remained close to the elderly during all tests for safety reasons to avoid any accidents/falls), was timed using the digital stopwatch function in a Nokia X2-01 cellular phone (Manaus, Brazil).

The participants were instructed to stay as still as possible. In the stances with eyes open, the volunteers were instructed to look at a black circle $5 \mathrm{~cm}$ in diameter, which was placed in front of the volunteer at a distance of $1.5 \mathrm{~m}$ at eye level ${ }^{16}$. Those individuals who needed their usual corrective lenses used them. 
Participants who failed to maintain the stance for the predetermined time had the stance removed from the statistical analysis. In the single-leg stance analysis, because some elderly individuals could not remain in the stance for the stipulated time of data collection (i.e. 30 seconds), only those who managed to stay in the single-leg stance for at least 5 seconds (i.e. maximum time that the majority of elderly managed to stay in the single-leg stance) were included. The performance of the tandem stance with eyes closed was achieved by 15 elderly in the WC group and 26 elderly in the NC group. In the single-leg stance, two elderly from each group failed to perform the test, and the analysis was conducted with 15 and 25 elderly in each group, respectively (Figure 1).

The force platform enabled the examiners to infer the distribution of force at four points, allowing for the analysis of balance, with quantifications of the amplitude and mean velocity of anterior-posterior (AP) and medial-lateral (ML) displacements of the COP and the total displacement area of the COP. The mean amplitude of sway, which corresponded to the variability around the mean of a time series and was used to estimate the stability of the $\mathrm{COP}^{17,18}$, was calculated by subtracting the mean of the values within the attempt, and then calculating the mean variance of the values of this attempt. The mean velocity was determined by dividing the total displacement of the COP (i.e. the sum of the scale displacement) in each direction for the total time of the attempt ${ }^{19}$. The area was calculated using the area of the ellipse method, which corresponded to the dispersion of the COP data according to the calculation of the area of the statokinesigram ${ }^{15}$. During data collection, the participants stayed on the force platform, barefoot with feet apart at shoulder width and arms along the sides of the body (in double-leg stance) or with one foot in front of the other (in tandem stance) or supported by one foot only (in single-leg stance).

SPSS software (version 18.0 Windows, Inc., Chicago, IL) was used for the statistical analysis. The Shapiro-Wilk test was used to verify the normality of the data, and logarithmic transformation was employed to confirm the non-normal distribution of data related to variables evaluated on the force platform. To compare the anthropometric characteristics between the groups, the Student's t test was used. To compare the various stances and conditions with each other, the Friedman analysis was used, followed by a post-hoc Wilcoxon test with Bonferroni correction. For analysis of length of stay in the single-leg stance and to compare the various conditions of posturography between groups, the Kruskal-Wallis test was used, followed by a posthoc Mann-Whitney test with Bonferroni correction. The Spearman correlation test was used to correlate the length of stay in the single-leg stance (right and left legs) and the variables of posturography. The level of significance adopted was $5 \%$.

\section{Results}

The variables of age, weight, height and body mass index (BMI) (Table 1) of the WC and NC of imbalance groups were compared to test the homogeneity between groups. The Student's $t$ test indicated that there were no differences in these variables $(\mathrm{p}>0.05)$.

Figure 2A shows the values of the COP area under the eight different situations evaluated, with the WC

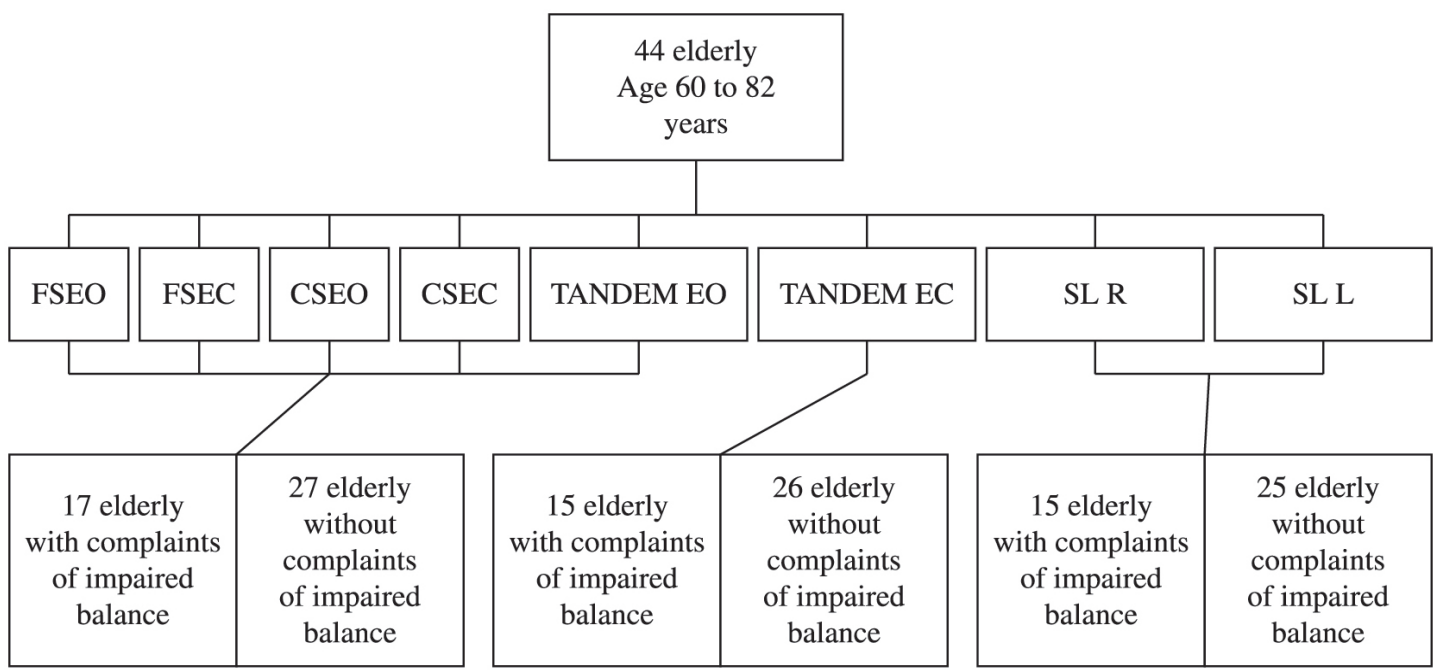

Figure 1. Flowchart of the experimental design with the total sample. FSEO: firm surface, eyes open; FSEC, firm surface, eyes closed; CSEO: compliant surface, eyes open; CSEC: compliant surface, eyes closed; Tandem EO: tandem stance, eyes open; Tandem EC: tandem stance, eyes closed; SL R: standing on right foot only; SL L: standing on left foot only. 
and $\mathrm{NC}$ groups showing significant increases in the COP area when comparing the different stances to each other, revealing differences in sway depending on the stance adopted. Figure 2B shows the values of the mean COP velocity in the AP direction under the different situations evaluated. Figure $2 \mathrm{C}$ shows the

Table 1. Values for anthropometric data (age, height, weight and body mass index [BMI]) for 2 elderly groups with and without complaints of imbalance.

\section{Groups}

With complaints of impaired balance

Without complaints of impaired balance

\begin{tabular}{cccc}
$\begin{array}{c}\text { Age } \\
(\text { years })\end{array}$ & $\begin{array}{c}\text { Height } \\
(\mathbf{m})\end{array}$ & $\begin{array}{c}\text { Body Mass } \\
(\mathbf{k g})\end{array}$ & $\begin{array}{c}\text { BMI } \\
\left(\mathbf{k g} / \mathbf{m}^{2}\right)\end{array}$ \\
$67.18 \pm 5.31$ & $1.58 \pm 0.07$ & $71.75 \pm 11.21$ & $28.66 \pm 4.03$ \\
$65.41 \pm 3.53$ & $1.55 \pm 0.05$ & $65.81 \pm 9.51$ & $27.41 \pm 3.38$ \\
\hline
\end{tabular}
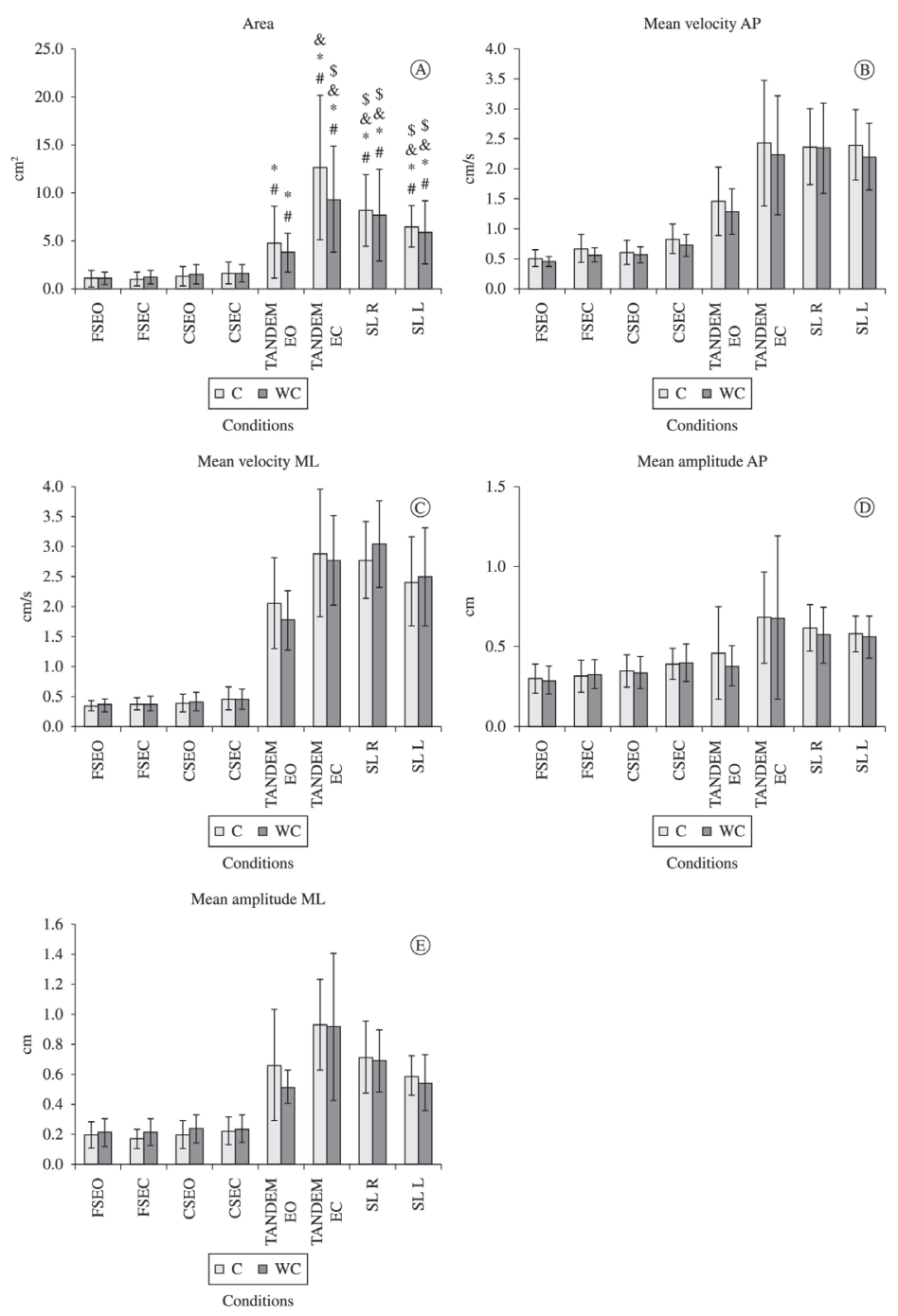

Figure 2. Means and standard deviations of posturography variables (i.e. area, mean velocity anterior-posterior, mean velocity mediallateral, mean amplitude anterior-posterior and mean amplitude medial-lateral) for 2 elderly groups with (WC) and without (NC) complaints of imbalance. FSEO: firm surface, eyes open; FSEC, firm surface, eyes closed; CSEO: compliant surface, eyes open; CSEC: compliant surface, eyes closed; Tandem EO: tandem stance, eyes open; Tandem EC: tandem stance, eyes closed; SL R: standing on right foot only; SL L: standing on left foot only. A) FSEO (\# p $<0.05$ vs Tandem EO, Tandem EC, SL R and SL L in groups WC and NC), FSEC (* p $<0.05$ vs Tandem EO, Tandem EC, SL R, SL L in groups WC and NC), CSEO ( \& p <0.05 vs Tandem EC, SL R, SL L in groups WC and NC), CSEC ( $\$$ p $<0.05$ vs SL R, SL L in group WC; and Tandem EC, SL R, SL L in group NC). 
values of the mean COP velocity in the ML direction. Figure 2D shows the mean AP amplitude values. Figure 2E shows the mean ML amplitude values.

For the analysis of time limit (Tlimit) in the single-leg stance, only the SINGLE L stance differed significantly between the WC and NC groups ( $p=0.01$ ), considering a 0.025 significance level, according to the Bonferroni corrections (Table 2).

The correlations between the length of stay in single-leg stance and the various variables analyzed by posturography are described in Table 3 . This test indicated a negative correlation between the length of stay in single-leg stance and the observed variables (Table 3 ).

\section{Discussion}

Postural control is considered good when the body sway is small ${ }^{20}$. However, the difficulty of the task is an important factor when assessing postural control in the elderly ${ }^{10}$ and the various conditions imposed, as these different tasks and their difficulty may suggest a greater reliance on one afferent system over another ${ }^{21}$.

In healthy elderly individuals with a stable base of support and in good lighting conditions, the proportion of reliance of the information travelling from the afferent sensory systems to the central nervous system (CNS) are $10 \%$ for the visual system, $70 \%$ for the somatosensory system and $20 \%$ for the vestibular system $^{21}$. However, the contribution of each sensory system is related to both the environmental conditions and the task $\mathrm{k}^{21}$. The hypothesis of reweighing or altering the percentage involvement of the different sensory systems is based on the capacity of the CNS to adapt to different conditions by adjusting the weight of information of each sensory system that controls balance. When a sensory system becomes inaccurate

Table 2. Time limits (Tlimit) in right and left single-leg stances for 2 elderly groups with and without complaints of imbalance.

\begin{tabular}{lccc}
\hline \multicolumn{1}{c}{ Tlimit (seconds) } & $\begin{array}{c}\text { With complaints of impaired } \\
\text { balance }\end{array}$ & $\begin{array}{c}\text { Without complaints of } \\
\text { impaired balance }\end{array}$ & p value \\
Single-Leg Stance (Right) & $19.42 \pm 9.89$ & $25.53 \pm 6.23$ & 0.087 \\
Single-Leg Stance (Left) & $19.43 \pm 9.34$ & $26.74 \pm 5.03$ & $0.013^{*}$ \\
\hline
\end{tabular}

${ }^{*} \mathrm{p}<0.025$ according to the Bonferroni correction.

Table 3. Correlation between Tlimit of one single-leg stance and posturography variables (mean velocity AP and ML, mean amplitude $\mathrm{AP}$ and ML and area) between 2 elderly groups with and without complaints of imbalance.

\begin{tabular}{|c|c|c|c|c|c|}
\hline \multirow{2}{*}{$\begin{array}{c}\text { Posturography } \\
\text { variables }\end{array}$} & \multirow{2}{*}{$\begin{array}{c}\text { Statistic } \\
\text { (Spearman } \\
\text { Correlation) }\end{array}$} & \multicolumn{2}{|c|}{ With complaints of imbalance } & \multicolumn{2}{|c|}{ Without complaints of imbalance } \\
\hline & & $\begin{array}{l}\text { One single Leg R } \\
\text { stance Tlimit }\end{array}$ & $\begin{array}{l}\text { One single Leg L } \\
\text { stance Tlimit }\end{array}$ & $\begin{array}{l}\text { One single Leg R } \\
\text { stance Tlimit }\end{array}$ & $\begin{array}{c}\text { One single Leg } \mathbf{L} \\
\text { stance Tlimit }\end{array}$ \\
\hline Mean Velocity AP & $\begin{array}{l}\text { P Value } \\
\mathrm{r}_{\mathrm{s}} \text { (Correlation } \\
\text { Coefficient) } \\
\text { Correlation }\end{array}$ & $\begin{array}{l}0.00001 \\
-0.880 \\
\text { Strong } \\
\text { Negative }\end{array}$ & $\begin{array}{l}0.22 \\
-0.586\end{array}$ & $\begin{array}{l}0.147 \\
-0.293\end{array}$ & $\begin{array}{l}0.04 \\
-0.414 \\
\text { Weak } \\
\text { Negative }\end{array}$ \\
\hline Mean Velocity ML & $\begin{array}{l}\text { P Value } \\
\mathrm{r}_{\mathrm{s}} \text { (Correlation } \\
\text { Coefficient) } \\
\text { Correlation }\end{array}$ & $\begin{array}{l}0.5 \\
-0.189\end{array}$ & $\begin{array}{l}0.67 \\
-0.120\end{array}$ & $\begin{array}{l}0.58 \\
-0.112\end{array}$ & $\begin{array}{l}0.09 \\
-0.346\end{array}$ \\
\hline Mean Amplitude AP & $\begin{array}{l}\text { P Value } \\
\mathrm{r}_{\mathrm{s}} \text { (Correlation } \\
\text { Coefficient) } \\
\text { Correlation }\end{array}$ & $\begin{array}{l}0.002 \\
-0.734 \\
\text { Moderate } \\
\text { Negative }\end{array}$ & $\begin{array}{l}0.25 \\
-0.315\end{array}$ & $\begin{array}{l}0.46 \\
-0.149\end{array}$ & $\begin{array}{l}0.05 \\
-0.397 \\
\text { Weak } \\
\text { Negative }\end{array}$ \\
\hline $\begin{array}{l}\text { Mean Amplitude } \\
\text { ML }\end{array}$ & $\begin{array}{l}\text { P Value } \\
\mathrm{r}_{\mathrm{s}} \text { (Correlation } \\
\text { Coefficient) } \\
\text { Correlation }\end{array}$ & $\begin{array}{l}0.035 \\
-0.546 \\
\text { Moderate } \\
\text { Negative }\end{array}$ & $\begin{array}{l}0.037 \\
-0.541 \\
\text { Moderate } \\
\text { Negative }\end{array}$ & $\begin{array}{l}0.61 \\
-0.104\end{array}$ & $\begin{array}{l}0.15 \\
-0.296\end{array}$ \\
\hline Area & $\begin{array}{l}\text { P Value } \\
\mathrm{r}_{\mathrm{s}} \text { (Correlation } \\
\text { Coefficient) } \\
\text { Correlation }\end{array}$ & $\begin{array}{l}0.002 \\
-0.727 \\
\text { Moderate } \\
\text { Negative }\end{array}$ & $\begin{array}{l}0.026 \\
-0.571 \\
\text { Moderate } \\
\text { Negative }\end{array}$ & $\begin{array}{l}0.71 \\
-0.075\end{array}$ & $\begin{array}{l}0.046 \\
-0.402 \\
\text { Weak } \\
\text { Negative }\end{array}$ \\
\hline
\end{tabular}


or begins to fail, the CNS reduces the weight of or reliance on that system and relies more on others ${ }^{21,22}$.

When examining the various conditions and stances (i.e. when doing intragroup analysis), it was observed that in double-leg stance, the elderly had smaller sway of the COP compared to the tandem and single-leg stances, which had smaller support bases, and consequently, greater difficulty imposed by the task, a result that was expected due to the functional/compensatory adaptations of posture described by Strang et al. ${ }^{20}$. However, no differences were observed between the double-leg stances with and without foam or with eyes open or closed, most likely because they were less challenging stances for the study sample of young, independent, community-dwelling elderly.

There were no differences when comparing the groups of elderly WC and $\mathrm{NC}$ in terms of imbalance (i.e. using intergroup analysis). This finding could be due to the heterogeneity of the aging process. It is important to note that the aging process causes deficits in postural control; however, these changes do not occur in a linear fashion ${ }^{23}$. Thus, complaints of imbalance may be associated with the existence of initial impairments of different components of the postural system. In the present study, the focus was placed on sensory strategies.

In the literature, lateral instability, reflected by a higher mean ML amplitude, has been associated with future falls ${ }^{24}$, and elderly female fallers have higher ML sway in relation to non-fallers ${ }^{25}$. In regard to AP sway, AP displacement of the COP was more significant in fallers than in non-fallers, especially in the forward direction ${ }^{25}$. The lack of difference between the elderly WC and NC groups in terms of imbalance could also be explained by the absence of fallers in the study sample.

Although the single-leg stance is one of the most challenging stances, the variables related to posturography revealed no differences between the groups. However, the length of time maintaining this stance was sensitive enough to predict the decreased postural control that the WC group had for imbalance.

According to the literature, the time one is able to maintain a single-leg stance is sensitive for predicting both poor postural control and injurious fall $\mathrm{s}^{26}$, has good inter-rater reliability (intraclass correlation coefficient [ICC $]=0.75$ in elderly without impairments) and intra-rater reliability $(\mathrm{ICC}=0.73)^{11}$, and is an indicator of falls in the elderly over 70 years of age when the length of time in the stance is less than 30 seconds $^{27}$. In a study comparing fallers and non-fallers over the age of 50 performing the single-leg stance for 45 seconds, it was observed that fallers had a shorter length of time in the stance (mean of 9.6 seconds) compared to non-fallers (mean of 31.3 seconds) ${ }^{28}$. Lion et al. ${ }^{8}$ compared elderly women with and without complaints of dizziness and also observed poor performance in elderly individuals with dizziness in the 5-second single-leg clinical trial and other functional tests. As can be seen, the time set for the single-leg stance test can affect the interpretation of the results.

The results showed that only the time spent in the SINGLE L stance was sensitive for identifying deficits between the WC and NC groups for imbalance. Bohannon et al. ${ }^{29}$ reported that there was no difference between the length of time in the right or left single-leg stance. Any difference might be indicative of abnormalities in either leg or in some proximal component of postural control of the leg with the deficit ${ }^{29}$. Vieira et al. ${ }^{30}$ reported that the SINGLE Right stance was more stable than the SINGLE Left stance. This difference might be explained by the fact that the left prefrontal cortex could be more significant in postural corrections induced by intrinsic body sway ${ }^{30}$. Cortical and subcortical structures control the right side of the body in right-handed individuals regulating the low-magnitude feedback of the sensorimotor integration of different sensory source ${ }^{30}$. Our results suggest that in the SINGLE Left stance, this control of low-magnitude adjustments was not performed with the same effectiveness or in the same way as in the SINGLE Right stance, which would allow for greater sensitivity in the single-leg LEFT stance when taking into account the subtle deficits in postural control.

When analyzing the correlation between the posturography variables and the length of time in single-leg stance, a strong to moderate negative correlation (-0.54 to -0.8) was observed for the group with complaints of imbalance and a weak negative correlation $(-0.21$ to -0.41$)$ for the group without complaints of imbalance. This result was expected because the time variable was inversely proportional to the measurements of the posturographic variables. The greater the length of time in the position, the lower the values of the AP and ML amplitudes, mean velocities and the COP area, which would indicate better postural control.

Therefore, when assessing balance, the professional should be aware that objective, quantitative tests might not be sensitive enough to detect poor postural control in healthy, community-dwelling elderly individuals when the balance deficit is minimal. However, the 
clinical test for the single-leg stance could be used to evaluate postural control because the single-leg stance is already used in clinical practice and offers greater reliability according to the length of time in the stance ${ }^{28}$. The existence of imbalance complaints could be considered as indicative of subtle deficits in postural control and could be used to establish functional diagnostic and therapeutic targets for elderly individuals.

Based on this result, it could be inferred that, in clinical practice, elderly women with complaints of imbalance might not have postural control deficits detectable by means of objective tests, such as the posturography. However, they already show deficits in clinical tests, such as the length of time in a single-leg stance test. Thus, when observing signs of early deficits in postural control, preventive measures should be taken to avoid the first fall because, after the first fall, it has been reported that elderly individuals becomes more susceptible to additional fall episodes ${ }^{3}$.

Future longitudinal studies should be performed to assess whether elderly complaints of imbalance are related to poor postural control in the short- to medium-term.

\section{Study limitations}

This study has some limitations, including the following: 1) the results cannot be generalized to fragile or institutionalized elderly because the study was conducted with healthy, young-old, from the community; 2) the results cannot be extrapolated to men or all elderly in general because the study included only women; and 3) although the single-leg stance test appeared to be a clinical test that was sensitive enough to detect deficits in postural control, it was not used as a form of group division comparing the length of time in this stance.

\section{Conclusion}

The study showed no difference in the COP sway between elderly women with or without complaints of imbalance. The subjective analysis of the complaint of imbalance was not related to the objective analysis (posturography); however, the single-leg stance clinical test appeared to be sensitive enough to identify subtle deficits in postural control. Self-reported imbalance is a simple questioning tool likely to detect impairments in postural control; however, it should be used together with clinical tests because the aging process is heterogeneous. The single-leg stance clinical test indicated that elderly women with complaints of imbalance have shorter lengths of time in the stance position compared to elderly women with no complaints of imbalance, suggesting poor postural control.

\section{Acknowledgements}

The authors thank the Fundação de Amparo à Pesquisa do Estado de São Paulo (FAPESP - 2012/05666-4) for their financial support; the Evaluation and Rehabilitation of Balance Laboratory (Laboratório de Avaliação e Reabilitação do Equilíbrio - LARE); the Department of Biomechanics, Medicine and Rehabilitation of the Locomotor System at the FMRP-USP; the Ribeirão Preto Medical School, University of São Paulo; the volunteers who participated in this study; Marcela Fernandes Silva for her commitment and dedication to this study and Matheus Machado Gomes for the knowledge shared.

\section{References}

1. Nicolussi AC, Fhon JR, Santos CA, Kusumota L, Marques S, Rodrigues RA. Quality of life in elderly people that have suffered falls: integrative literature review. Cien Saude Colet. 2012;17(3):723-30. http://dx.doi.org/10.1590/ S1413-81232012000300019. PMid:22450414

2. Gama ZAS, Gómez-Conesca A. Factores de riesgo de caídas en ancianos: revisión sistemática. Rev Saúde Pública 2008;42(5):946-56.

3. Perracini MR, Ramos LR. Fall-related factors in a cohort of elderly community residents. Rev Saude Publica. 2002;36(6):709-16. http://dx.doi.org/10.1590/S003489102002000700008. PMid:12488937

4. Jenkyn KB, Hoch JS, Speechley M. How much are we willing to pay to prevent a fall? Cost-effectiveness of a multifactorial falls prevention program for communitydwelling older adults. Can J Aging. 2012;31(2):121-37. http:// dx.doi.org/10.1017/S0714980812000074. PMid:22621837

5. Maia BC, Viana PS, Arantes PMM, Alencar MA. Consequences of falls in older people living in the community. Rev Bras Geriatr Gerontol. 2011;14(2):381-93. http://dx.doi.org/10.1590/ S1809-98232011000200017.

6. Lopes KT, Costa DF, Santos LF, Castro DP, Bastone AC. Prevalence of fear of falling among a population of older adults and its correlation with mobility, dynamic balance, risk and history of falls. Rev Bras Fisioter. 2009;13(3):223-9. http://dx.doi.org/10.1590/S1413-35552009005000026.

7. Baloh RW, Jacobson KM, Enrietto JA, Corona S, Honrubia $\mathrm{V}$. Balance disorders in older persons: quantification with posturography. Otolaryngol Head Neck Surg. 1998;119(1):8992. http://dx.doi.org/10.1016/S0194-5998(98)70177-9. PMid:9674519 
8. Lion A, Spada RS, Bosser G, Gauchard GC, Anello G, Bosco $\mathrm{P}$, et al. Biological determinants of postural disorders in elderly women. Int J Neurosci. 2013;123(1):24-30. http:// dx.doi.org/10.3109/00207454.2012.722570. PMid:22909193

9. Singh NB, Taylor WR, Madigan ML, Nussbaum MA. The spectral content of postural sway during quiet stance: influences of age, vision and somatosensory inputs. J Electromyogr Kinesiol. 2012;22(1):131-6. http://dx.doi. org/10.1016/j.jelekin.2011.10.007. PMid:22100720

10. Prioli AC, Cardozo AS, Freitas Júnior PB, Barela JA. Task demand effects on postural control in older adults. Hum Mov Sci. 2006;25(3):435-46. http://dx.doi.org/10.1016/j. humov.2006.03.003. PMid:16647771

11. Mancini M, Horak FB. The relevance of clinical balance assessment tools to differentiate balance deficits. Eur J Phys Rehabil Med. 2010;46(2):239-48. PMid:20485226.

12. Günendi Z, Taskiran ÖÖ, Uzun MK, Öztürk GT, Demirsoy N. Reliability of quantitative static and dynamic balance tests on kinesthetic ability trainer and their correlation with other clinical balance tests. J PMR Sci. 2010;13:1-5.

13. Folstein MF, Folstein SE, McHugh PR. "Mini-mental state". A practical method for grading the cognitive state of patients for the clinician. J Psychiatr Res. 1975;12(3):189-98. http:// dx.doi.org/10.1016/0022-3956(75)90026-6. PMid:1202204

14. Guerraz M, Shallo-Hoffmann J, Yarrow K, Thilo KV, Bronstein AM, Gresty MA. Visual control of postural orientation and equilibrium in congenital nystagmus. Invest Ophthalmol Vis Sci. 2000;41(12):3798-804. PMid:11053279.

15. Duarte M, Freitas SM. Revision of posturography based on force plate for balance evaluation. Rev Bras Fisioter. 2010;14(3):183-92. http://dx.doi.org/10.1590/S141335552010000300003. PMid:20730361

16. Paulus WM, Straube A, Brandt T. Visual stabilization of posture. Physiological stimulus characteristics and clinical aspects. Brain. 1984;107(Pt 4):1143-63. http://dx.doi. org/10.1093/brain/107.4.1143. PMid:6509312

17. Bonfim TR, Grossi DB, Paccola CA, Barela JA. Additional sensory information reduces body sway of individuals with anterior cruciate ligament injury. Neurosci Lett. 2008;441(3):257-60. http://dx.doi.org/10.1016/j.neulet.2008.06.039. PMid:18582536

18. Dutil M, Handrigan GA, Corbeil P, Cantin V, Simoneau $\mathrm{M}$, Teasdale N, et al. The impact of obesity on balance control in community-dwelling older women. Age (Dordr). 2013;35(3):883-90. http://dx.doi.org/10.1007/s11357-0129386-x. PMid:22318311

19. Abreu DC, Gomes MM, Santiago HA, Herrero CF, Porto MA, Defino HL. What is the influence of surgical treatment of adolescent idiopathic scoliosis on postural control? Gait Posture. 2012;36(3):586-90. http://dx.doi.org/10.1016/j. gaitpost.2012.05.019. PMid:22743026

20. Strang AJ, Haworth J, Hieronymus M, Walsh M, Smart LJ Jr. Structural changes in postural sway lend insight into effects of balance training, vision, and support surface on postural control in a healthy population. Eur J Appl
Physiol. 2011;111(7):1485-95. http://dx.doi.org/10.1007/ s00421-010-1770-6. PMid:21165641

21. Horak FB. Postural orientation and equilibrium: what do we need to know about neural control of balance to prevent falls? Age Ageing. 2006;35(Suppl 2):ii7-11. http://dx.doi. org/10.1093/ageing/afl077. PMid:16926210

22. Pasma JH, Boonstra TA, Campfens SF, Schouten AC, Van der Kooij H. Sensory reweighting of proprioceptive information of the left and right leg during human balance control. J Neurophysiol. 2012;108(4):1138-48. http://dx.doi. org/10.1152/jn.01008.2011. PMid:22623486

23. El Haber N, Erbas B, Hill KD, Wark JD. Relationship between age and measures of balance, strength and gait: linear and non-linear analyses. Clin Sci (Lond). 2008;114(12):719-27. http://dx.doi.org/10.1042/CS20070301. PMid:18092948

24. Piirtola M, Era P. Force platform measurements as predictors of falls among older people - a review. Gerontology. 2006;52(1):1-16. http://dx.doi.org/10.1159/000089820. PMid:16439819

25. Merlo A, Zemp D, Zanda E, Rocchi S, Meroni F, Tettamanti $\mathrm{M}$, et al. Postural stability and history of falls in cognitively able older adults: the Canton Ticino study. Gait Posture. 2012;36(4):662-6. http://dx.doi.org/10.1016/j.gaitpost.2012.06.016. PMid:22832469

26. Vellas BJ, Wayne SJ, Romero L, Baumgartner RN, Rubenstein LZ, Garry PJ. One-leg balance is an important predictor of injurious falls in older persons. J Am Geriatr Soc. 1997;45(6):735-8. PMid:9180669.

27. Domínguez-Carrillo LG, Arellano-Aguilar G, Leos-Zierold H. Unipedal stance time and fall risk in the elderly. Cir Cir. 2007;75(2):107-12. PMid:17511906.

28. Hurvitz EA, Richardson JK, Werner RA, Ruhl AM, Dixon MR. Unipedal stance testing as an indicator of fall risk among older outpatients. Arch Phys Med Rehabil. 2000;81(5):58791. http://dx.doi.org/10.1016/S0003-9993(00)90039-X. PMid:10807096

29. Bohannon RW, Larkin PA, Cook AC, Gear J, Singer J. Decrease in timed balance test scores with aging. Phys Ther. 1984;64(7):1067-70. PMid:6739548.

30. Vieira O Jr, Coelho DB, Teixeira LA. Asymmetric balance control between legs for quiet but not for perturbed stance. Exp Brain Res. 2014;232(10):3269-76. http://dx.doi. org/10.1007/s00221-014-4018-6. PMid:24954557

\author{
Correspondence \\ Erika Harumi Tanaka \\ Avenida Bandeirantes, 3900 \\ CEP 14049-900, Ribeirão Preto, SP, Brasil \\ e-mail: erika.tanaka@gmail.com
}

